points. First, CMV should be considered in patients in whom GvHD does not respond to appropriate treatment. In this case, CMV viraemia was concomitant with the relapse in GvHD and this seems to support the hypothesis that CMV may increase the severity of GvHD by synergistically enhancing the graft versus host reaction. Second, the differentiation of GvHD from CMV is difficult histologically and immunohistochemistry is useful in this regard. Third, in spite of detectable CMV viraemia, repeated urine and throat swab specimens were negative for CMV by culture until the terminal stages of the illness ( 74 days after BMT).

Finally, CMV viraemia was not detectable by culture 56 days after BMT. However, the virus was detectable in the peripheral blood by PCR up to the time of death, and death was caused by disseminated CMV infection. Herman $e t$ al have recently suggested that the PCR may have a role in the early detection of CMV in the period immediately after transplantation before any clinical symptoms of viraemia or GvHD are evident. ${ }^{8}$

Using agarose gel electrophoresis with ethidium bromide staining to detect the amplified PCR product, the technique that we used does not detect CMV DNA in the peripheral blood of healthy seropositive subjects. Furthermore, we have so far studied 22 transplant recipients, 13 of whom were seropositive for CMV before surgery, and have obtained negative PCR results for $\mathrm{CMV}$ at several time intervals after transplantation in 21 patients, all of whom were shown not to have been actively infected with CMV. This preliminary evidence suggests that PCR may be able to differentiate clinically important active CMV infection from subclinical infection. As profound immunosuppression may facilitate the reactivation of latent CMV, the differentiation of active CMV infection by PCR may be important in the management of immunosuppressed patients.

We thank Dr S J Proctor for permission to publish data about his patient.

1 O'Reilly RJ. Allogeneic bone marrow transplantation: Current status and future directions. Blood 1983;62:941-64.
Miller W, Flynn P, McCullough J, et al. Cytomegalovirus infection after bone marrow transplantation: an association with acute graft-versus-host disease. Blood 1986;67:1162-7.

3 Meyers JD, Fluornoy N, Thomas ED. Risk factors for cytomegalovirus infection after human marrow transplantation. F Infect Dis $1986 ; 153: 478-88$.

4 Lonnquist B, Ringdén O, Wahren B, Gahrton G, Lundgren $G$. Cytomegalovirus infection associated with and preceding chronic graft-versus-host disease. Transplantation ing chronic graft

5 Bôstrom L, Ringdén O, Sundberg B, Linde A, Tollemar F, Nilsson B. Pre-transplant herpes virus serology and acute Nilsson B. Pre-transplant herpes virus serology and acute
graft-versus-host disease. Transplantation 1988;46: graft-versus-

6 Sviland L, Pearson ADJ, Eastham EJ, et al. Histological features of skin and rectal biopsy specimens after autologous and allogeneic bone marrow transplantation. $\mathcal{f}$ Clin Pathol 1988;41:148-54,

7 Demmler EJ, Burrone CJH, Schimber CW, Ray RA. Detection of cytomegalovirus in urine from newborns by using polymerase chain reaction DNA amplification. $\mathcal{F}$ Infect Dis 1988;158:1177-84.

8 Herman Ė, Steidle M, Vallbracht A, Saal JG, Ehninger G, Muller CA. Early occurrence of human cytomegalovirus infection after bone marrow transplantation by the polymerase chain reaction technique. Blood 1991; 77:1 104-10.

\section{Department of Clinical Chemistry, Royal Hallamshire Hospital, Sheffield S10 2JF ARW Forrest JH Galloway \\ Department of Histopathology, Rotherham District General Hospital, Rotherham DN Slater determining the risk to those carrying out necropsies of the bodies of victims of cyanide poisoning is the amount of cya- several ways in which the theoretical risk inherent in carrying out such necropsies could be reduced, such as the use of a full face respirator, or the removal, intact, of the upper gastrointestinal tract to a fume cupboard for examination.}

Correspondence to: Dr ARW Forrest Accepted for publication 30 October 1991

It has been suggested that those involved in the

\title{
The cyanide poisoning necropsy: an appraisal of risk factors
}

\author{
A R W Forrest, J H Galloway, D N Slater
}

\begin{abstract}
Blood cyanide concentrations were measured in samples obtained from a pathologist before and after carrying out a necropsy on the body of a victim of cyanide poisoning. There was no significant increase in his blood cyanide concentration after carrying out the procedure. It is suggested that an important factor in nide remaining in the stomach. There are
\end{abstract} post mortem examination of the bodies of those dying of overdoses of cyanide may be at risk of exposure to toxic concentrations of cyanide. ${ }^{1}$ We recently had the opportunity to assess this risk in practice.

A 40 year old industrial chemist was found dead at home. At the scene were copious amounts of vomit and a note stating that he had taken cyanide with the intention of ending his life. A post mortem examination was carried out within 24 hours of the discovery of the body by an experienced pathologist (DNS) in a post mortem suite equipped with down draught ventilation. This ventilation system produces at least 12 changes of air per hour. Both the pathologist and the anatomical pathology technician in attendance wore antisplash : facemasks and "double" surgical masks. The time taken to carry out the necropsy was 35 minutes, the amount of dissection carried out being the minimum necessary to establish the cause of death. Of necessity this included opening the upper gastrointestinal tract for the recovery of gastric 
contents for toxicological analysis. Only a small amount of stomach content $(50 \mathrm{ml})$ was present and no powder residue was seen. No smell of "burnt almonds", suggestive of hydrogen cyanide, or any ill effects were noted by either the pathologist or the anatomical pathology technician. Venous blood samples were taken from the pathologist immediately before and after the necropsy.

The samples submitted were analysed for the presence of cyanide by an unpublished head-space gas chromatographic method which has an analytical precision of more than $5 \%$. The pathologist, a non-smoker, had blood cyanide concentrations of $175 \mathrm{~m} / \mathrm{l}$ before necropsy and $195 \mathrm{~m} / 1$ after necropsy. These concentrations are within our reference range for non-smokers (105-295 m/l). The subject of the necropsy had a blood cyanide concentration of $43.7 \mathrm{~m} / 1$ and a stomach content cyanide concentration of $2 \cdot 2 \mathrm{~g} / \mathrm{l}$. The volume of the stomach content was only $50 \mathrm{ml}$. Thus the total cyanide recovered from the stomach content was only $110 \mathrm{mg}$.

Although the increase in the blood cyanide concentration of the pathologist after the necropsy was probably a real one, given the precision of the assay, it was not a significant increase toxicologically.

We suggest that one of the limiting factors that determines the risk to those in the post mortem suites when such cases are being examined may be the amount of cyanide remaining in the stomach. The feature which distinguishes the case reported by Andrews et al from that reported here is that their case had some 50 times more cyanide remaining in the stomach content than did our case. A surgical mask may provide some protection against the inhalation of dry sodium cyanide dust, but it will provide no protection whatsoever against the hydrogen cyanide evolved when cyanide salts come into contact with gastric acid. When the stomach is opened hydrogen cyanide, at a concentration well in excess of the threshold limit value, may be released into the atmosphere. Under such circumstances complete protection may necessitate the use of a full face respirator fitted with a B2 cartridge which meets the specification defined in British
Standard BS EN 141:1991. ${ }^{2}$ Such a respirator would provide protection for at least $25 \mathrm{~min}$ utes against an atmospheric concentration of hydrogen cyanide of $5.6 \mathrm{mg} / \mathrm{l}$. It is unlikely that the concentration of cyanide in a modern post mortem room would reach such concentrations.

Where such respirators are not available, or when the pathologist does not wish to wear one, an alternative procedure, which would reduce the risk of cyanide exposure somewhat, would be to tie off the upper gastrointestinal tract in situ and to remove it intact to a safety cabinet or fume cupboard for further examination and recovery of the contents. If the stomach contents are split the spillage should be immediately doused with copious amounts of bleaching powder or sodium hypochlorite solution. ${ }^{3}$

We conclude that necropsy can be safely carried out by an experienced pathologist in cases of cyanide ingestion. In such cases the prudent prosector should consider wearing a full face respirator and, in any case, take particular care when examining the upper gastrointestinal tract.

Finally, we were concerned to learn that the spouse of the victim in this case cleaned up the vomitus left at the scene, after the removal of the body, with normal household cleaning agents without taking any special precautions. Fortunately, she apparently sustained no ill effects. In such cases investigators and emergency services should be prepared to give advice on any special precautions that need to be taken after the investigation at the scene has been completed.

We are grateful to Dr Brian Cormack, of 3M United Kingdom PLC, for much helpful advice and to Dr P Taylor, who painlessly collected the blood samples from DNS

1 Andrews JM, Sweeney ES, Grey TC, Wetzel T. The biohazard potential of cyanide poisoning during postmortem examination. F For Sci 1989;34:1280-4.

2 BSI. Specification for gas filters and combined filters used in respiratory protection equipment. BS EN 141, London: British Standards Institute. 1991.

3 May \& Baker. Material Safety Data Sheets. Manchester: May \& Baker Laboratory Products, 1991:191. 